\title{
Mandibular Parasymphysis Fractures: Assesement of Pattern and Complications Following Open Reduction and Internal Fixation
}

\section{Sunil Kumar Panjabi ${ }^{1}$, Munir Ahmed Banglani ${ }^{2}$, Abdul Wahid Bhangwar ${ }^{3}$, Salman Shams ${ }^{4 *}$, Lovekesh Kumar ${ }^{5}$ and Taimoor Ali Khan ${ }^{6}$}

${ }^{1}$ Associate Professor Oral and Maxillofacial Surgery, Liaquat University of Medical and Health Sciences, Pakistan

${ }^{2}$ Associate Professor Oral Biology, Liaquat University of Medical and Health Sciences, Pakistan

${ }^{3}$ Registrar Oral and Maxillofacial Surgery, Liaquat University Hospital, Pakistan

${ }^{4}$ Senior Lecturer Oral and Maxillofacial Surgery, Liaquat University of Medical and Health

Sciences, Pakistan

${ }^{5}$ Senior Registrar Oral Medicine, Dow University of Health Sciences, Pakistan

${ }^{6}$ Resident Oral and Maxillofacial Surgery, Liaquat University of Medical and Health

Sciences, Pakistan

*Corresponding Author: Salman Shams, Senior Lecturer Oral and Maxillofacial

Surgery, Liaquat University of Medical and Health Sciences, Pakistan.

DOI: $10.31080 /$ ASDS.2020.04.0788
Received: February 05, 2020

Published: February 20, 2020

(C) All rights are reserved by Salman Shams., et al.

\begin{abstract}
Objective: To assess the pattern of presentation of mandibular parasymphysis fracture and its complications following open reduction and internal fixation (ORIF).

Setting: This study was conducted at oral and Maxillofacial Surgery Department, Faculty of Dentistry, Liaquat University Hospital Hyderabad, Jamshoro from January 2017 to December 2018.

Methodology: 83 patients of either gender with age above 18 years having mandibular non comminuted parasymphysis fractures were included in the study. All the patients were treated with Open reduction internal fixation (ORIF) under general anesthesia with no maxillomandibular fixation. Postoperatively patients were assessed for complications like plate exposure, non union, malocclusion, wound infection and numbness.

Results: Males were affected more than females. Majority of patients encountered were in age range of 21 to 30 years (37.34\%). Road traffic accident (55.42\%) was main cause of trauma in this study followed by fall. Plate exposure was seen in 07 patients (8.43\%), followed by wound infection in 5 patients (6.02\%).

Conclusion: Open reduction with internal fixation offers better outcomes in the management of Parasymphysis fracture.

Keywords: Assessment; Parasymphysis; Fracture; ORIF; Complication
\end{abstract}

\section{Introduction}

The mandible is the area of the face with major incidence of fracture. Its prominence and position in the skeletal face predispose to frequent traumas [2]. These mandible fractures are of great importance as they lead to varying degree of physical, functional and cosmetic disfigurement they may cause [2].

The mandibular fractures outnumber zygomatic and maxillary fractures by a ratio of 6:2:1, respectively [3]. The occurrence of fa- 
cial injuries tends to be high compared to injuries in other parts of the body because the face is without a protective covering and the mandible the most prominent bone in this region of the body [4].

Various studies have revealed that anterior mandible (symphysis and parasymphysis) is the second most frequent site among mandibular fractures [5]. Mandibular Parasymphyseal fractures lead to the loss of occlusion with step deformity formation. Forces of compression acting on the inferior border and forces of tension acting on the superior border tend to pull the segments apart creating the gap/ step. Mandibular unfavorable Parasymphyseal fractures need to be treated by open reduction and internal fixation to compensate both the forces and form a neutral zone [6].

The treatment options for the reduction and fixation of mandibular symphysis and parasymphysis fractures has evolved significantly over the past few years. The trends have changed from the methods of closed reduction and external fixation to the methods of open reduction and internal fixation [6,7]. Open reduction and internal fixation has the advantage of early restoration to normal masticatory function, without the need for inter maxillary fixation.

Rigid fixation of mandible fractures allows early mobilization and restoration of jaw function and airway control; improves nutritional status, speech, oral hygiene and patient comfort; and allows early return to the workplace [8]. In this study we will see the pattern of presentation of parasymphysis fracture and compare the complication rates with other studies of world.

\section{Data collection procedure}

This descriptive prospective study was carried out at department of oral and maxillofacial surgery Liaquat university hospital Hyderabad/Jamshoro from January 2017 to December 2018.

Total 83 patients of either gender with age above 18 years having mandibular non communited parasymphysis fractures were included in the study. All the patients were treated with ORIF under general anesthesia with no maxillomandibular fixation. Intraoral, open rigid fixation of noncomminuted parasymphyseal fractures was performed by buccal sulcus incison and raising mucoperiosteal flap and then using a combination of 2 miniplates that were either a 4-hole or a 6-hole miniplate using monocortical screws. The miniplates were $1-\mathrm{mm}$ thick with a $2-\mathrm{mm}$ screw diameter. Routine postoperative IV antibiotics were prescribed to all patients for 1 week. Postoperatively patients were assessed after 2 weeks to 6weeks for complications like plate exposure, non union, malocclusion, wound infection and numbness. Patients who were diabetic and with any other systemic disorders were excluded from study.

\section{Results}

There were total 83 patients; among those 58 (69.87\%) were males and 25 (30.12\%) were females as shown in graph 1.

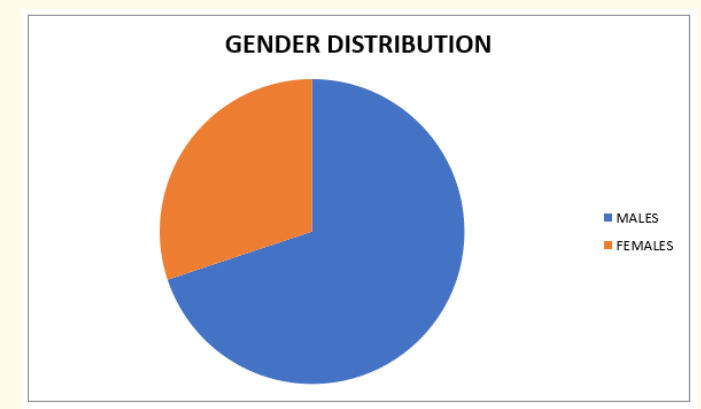

Graph 1: Percentage Of Patients According To Gender.

Road traffic accidents are common in our part of world due to traffic rules violation. So RTA is also a leading cause of parasymphysis fracture in this study followed by interpersonal violence, as shown in table 1.

\begin{tabular}{|l|c|c|}
\hline Cause of Fracture & No of Patients & $\mathbf{\%}$ \\
\hline Road Traffic Accident & 46 & $55.42 \%$ \\
\hline Fall & 21 & $25.30 \%$ \\
\hline Interpersonal Violence & 13 & $15.66 \%$ \\
\hline Sports injuries & 03 & $3.61 \%$ \\
\hline
\end{tabular}

Table 1: Shows Cause of Fracture.

Majority of patients seen were in $3^{\text {rd }}$ decade of life, which was followed by $4^{\text {th }}$ decade as shown in table 2 .

\begin{tabular}{|l|c|c|}
\hline Age Distribution & No of Patients & $\mathbf{\%}$ \\
\hline Above 18 andBelow 20 Years & 05 & $6.02 \%$ \\
\hline 21 to 30 Years & 31 & $37.34 \%$ \\
\hline 31 to 40 Years & 23 & $27.71 \%$ \\
\hline 41 to 50 Years & 14 & $16.86 \%$ \\
\hline 51 to 60 Years & 07 & $8.43 \%$ \\
\hline Above 60 Years & 03 & $3.61 \%$ \\
\hline
\end{tabular}

Table 2: Shows Cause of Fracture. 
Complication encountered were plate exposure, non union, malocclusion, wound infection and numbness. Exact proportion of each complication is shown in table 3 .

\begin{tabular}{|l|c|c|}
\hline Complications & No of Patients & $\mathbf{\%}$ \\
\hline Plate Exposure & 07 & $8.43 \%$ \\
\hline Non Union & 00 & $0 \%$ \\
\hline Malocclusion & 02 & $2.40 \%$ \\
\hline Wound Infection & 05 & $6.02 \%$ \\
\hline Numbness & 01 & $1.20 \%$ \\
\hline
\end{tabular}

Table 3: Complication Following ORIF.

\section{Discussion}

For the management of mandibular parasymphysis fracture, variety of options are available ranging from closed reduction MMF to open reduction by rigid osteosynthesis. This study is carried out to see the rate of complication by open reduction and internal fixation.

In this study the majority of patients reported were males that account for $69.87 \%$ of total cases. The reason for male predominance is because they are more involved in road traffic incidents and other sport and interpersonal violence. Most of the studies in world that comprises of mandibular parasymphysis fracture shows great predominance of males. Study carried out by Chowdhury S1 in 2016 shows 90\% involvement of males. Another study by Kumar SP9 also shows more occurrence of males in parasymphysis fractures.

Road traffic accidents were found to be the most frequent causative factors in this study ie $55.42 \%$ of total patients. This is due to increasing number of vehicles, high-speed driving, less use of seat belts and absence of airbags in most of the vehicles and alcohol abuse during driving. Adekeye [10] has reported that 74\% of mandibular fractures were due to RTA. This was also reported by Subhashraj., et al [11]. in a study done in South Indian city. The mechanism of hyperextension and hyperflexion of the head in traffic accidents makes it more vulnerable to fracture.

Majority of patients according to age groups encountered were in $3^{\text {rd }}$ decade of life, followed by fourth decade. This data was also supported by study carried out by Chowdhry $\mathrm{S}$ [1] where he dealt with $40 \%$ of patients in 21 to 30 years and $32 \%$ patients in 31 to 40 years.
Postoperative complication noticed following open reduction and internal fixation in between $1^{\text {st }}$ to 6 weeks were plate exposure in 07 cases, infection in 5 cases, malocclusion in 2 cases, temporary numbness in 01 case, while no patient was observed with non union at 6 weeks of course. Patients reported to infection were treated with antibiotics and results achieved. The infection rate was little higher when compared to Ugboko., et al [12]. who had $8.1 \%$. in contrast to our data, study carried out by Oruc M., et al [13]. showed no patient with infection. However, in an earlier study [14], poor oral conditions were cited as a factor in the development of infection and non-union. Patients with plate exposure were subsequently managed with warm salty water rinses and did not require hardware removal. Numbness is a frustrating complication, according to our findings, we can say that sensory problems are transient most of the time, and they are mostly related to the traction forces and edema. To overcome malocclusion a revision surgery was performed and results were satisfactorily achieved.

\section{Conclusion}

Parasymphyseal mandible fractures can be treated effectively with 2 miniplates using monocortical screws. All patients in this series achieved bony union with minimal complications.

The advantages of using 2 miniplates on Para symphyseal fractures is easy plate adaptability, no need for prolonged MMF unless indicated, and provision of adequate rigid fixation with minimal complications.

\section{Bibliography}

1. Chowdhury S., et al. "Clinical evaluation of healing of mandibular parasymphysis fractures with teeth in the fracture line". Update Dental College Journal 6.2 (2016): 06-12.

2. Hassan SG., et al. "Mandibular condyle fractures; a 2 years study at liaquat university hospital". The Professional Medical Journal 23.6 (2016): 705-708.

3. Senthilkumar R., et al. "Analysis of the Outcome of Mandible Fracture Management". IJSR - International Journal of Scientific Research 5.3 (2017): 179-184.

4. Vyas A., et al. "A study of mandibular fractures over a 5-year period of time: A retrospective study". Contemporary Clinical Dentistry 5 (2014): 452-455.

5. Abdullah S., et al. "Anterior mandible and condylar fracture; a comparative evaluation of open and closed reduction". The Professional Medical Journal 26.1 (2019): 35-39. 
6. Kanwaldeep Singh Soodan., et al. "Mandibular Parasymphyseal Fracture and its Management: A Case Report". Acta Scientific Dental Sciences 2.8 (2018): 39-41.

7. Ali Z., et al. "Mandibular symphysis fractures; comparison of conventional mini plates versus $3 \mathrm{~d}$ mini plates in the fixation of isolated mandibular symphysis fractures in Abbasi Shaheed Hospital Karachi-- a clinical study". The Professional Medical Journal 25.6 (2018): 815-822.

8. El-Anwar MW and El-Ahl MAS. "Open Reduction and Internal Fixation of Mandibular Fracture without Rigid Maxillomandibular Fixation". International Archives of Otorhinolaryngology 19 (2015): 314-318.

9. Kumar SP., et al. "Influence of anatomical variation of canine in parasymphyseal fracture: A retrospective studyInfluence of anatomical variation of canine in parasymphyseal fracture: A retrospective study". Journal of Indian Academy of Oral Medicine and Radiology 3 (2016): 33-38.

10. Adekeye EO. "The pattern of fractures of the facial skeleton in Kaduna, Nigeria. A survey of 1,447 cases". Oral Surgery, Oral Medicine, Oral Pathology, and Oral Radiology 49 (1980): 491495.

11. Sirimaharaj W and Pyungtanasup K. "The epidemiology of mandibular fractures treated at Chiang Mai University Hospital: A review of 198 cases". Journal of the Medical Association of Thailand 91 (2008): 868-874.

12. Oginni FO., et al. "Motorcycle-related maxillofacial injuries among Nigerian intracity road users". Journal of Oral and Maxillofacial Surgery 64 (2006): 56-62.

13. Oruc M., et al. "Analysis of Fractured Mandible Over Two Decades". Journal of Craniofacial Surgery 27 (2016): 1457-1461.

14. Zachariades $\mathrm{N}$ and Papademetriou I. "Complications of treatment of mandibular fractures with compression plates". Oral Surgery, Oral Medicine, Oral Pathology, and Oral Radiology 79 (1995): 150-153.

\section{Assets from publication with us}

- Prompt Acknowledgement after receiving the article

- Thorough Double blinded peer review

- Rapid Publication

- Issue of Publication Certificate

- High visibility of your Published work

Website: www.actascientific.com/

Submit Article: www.actascientific.com/submission.php

Email us: editor@actascientific.com

Contact us: +919182824667 